\title{
The Density of Titanium(IV) Oxide Liquid
}

\author{
Donald B. Dingwell* \\ Bayerisches Geo-institut, Universität Bayreuth, W8580 Bayreuth, Federal Republic of Germany
}

\begin{abstract}
The density of $\mathrm{TiO}_{2}$ liquid in equilibrium with air has been measured at $1875^{\circ}$ to $1925^{\circ} \mathrm{C}$ using an Ir double bob Archimedean method. The melt density data have been combined with data extrapolated from the $\mathrm{CaSiO}_{3}-\mathrm{TiO}_{2}$ join at $1600^{\circ} \mathrm{C}$. A combined fit to these density data yields the following description of the density of liquid $\mathrm{TiO}_{2}: \rho=$ $3.7611-0.00028 T\left({ }^{\circ} \mathrm{C}\right)$, in the temperature range of $1600^{\circ}$ to $1925^{\circ} \mathrm{C}$. This expansivity value is consistent with those obtained on $\mathrm{TiO}_{2}$-rich melts using a Pt-based system at lower temperature and with multicomponent oxide data. The similarity between the volume of liquid $\mathrm{TiO}_{2}$ and that of crystalline rutile implies a dominantly octahedral coordination of $\mathrm{Ti}$ in the liquid state. [Key words: titanium oxide, liquids, density, equilibrium, air.]
\end{abstract}

\section{Introduction}

$\mathbf{T}$ HE density of oxide liquids is an important factor controlling their behavior during processes of crystal-liquid fractionation. Such processes occur during geological rock formation and industrial processing involving slags. The liquid compositions in both cases are complex multicomponent systems with respect to the cations present but dominated by oxygen in the anionic component. Measurements of the density of simple end member components of these liquids are useful for the construction of completely general models for the structure and thermodynamics of such systems. Toward the goal of a complete description of such liquid densities, the densities of some simple liquid systems are under investigation. This paper presents the first data from an experimental system allowing the determination of liquid densitics in equilibrium with air up to at least $2000^{\circ} \mathrm{C}$. The first (to the best of our knowledge) measurements of the density of liquid $\mathrm{TiO}_{2}$ are presented as an example of the technique.

\section{Method}

The starting material for the generation of $\mathrm{TiO}_{2}$ liquid was $2-\mu \mathrm{m}$ powder of $\mathrm{TiO}_{2}(99.8 \%$, Alfa). The powder was loaded directly into an $\mathrm{Ir}$ crucible $(2.5-\mathrm{cm}$ inner diameter, $5.1 \mathrm{~cm}$ height). The Ir crucible was then wrapped in $\mathrm{ZrO}_{2}$ felt and placed in a tight-fitting $\mathrm{MgO}$ tube. This assembly was bottom loaded into the inner chamber of the high-temperature furnace.

The furnace was a commercially available model (VHT 2100 LINN HighTherm GmbH, Eschenfelden, FRG) (Fig. 1). Its special features are an inner chamber constructed from bubbleform $\mathrm{ZrO}_{2}$ and two independent sets of heating elcments. The outer set arc MoSi, hairpin elements which prehcat to $1700^{\circ} \mathrm{C}$. These elements sit in wells within the bubbleform $\mathrm{ZrO}_{2}$ walls. The second set of heating elements

D. P. H. Hasselman-contributing editor

Manuscript No. 196688. Received May 21, 1991; approved August 3, 1991

This work was partially supported by a Leibniz-Prcis to F. A. Seifert

* Member, American Ceramic Society. are $\mathrm{ZrO}_{2}$ with $(\mathrm{La}, \mathrm{Sr}) \mathrm{CrO}_{3}$ end pieces. These elements become sufficiently electrically conducting at $1250^{\circ} \mathrm{C}$ and are capable of heating to $2150^{\circ} \mathrm{C}$ in the present configuration.

The furnace was operated via electronic programmable temperature controllers. The preheating was controlled by a type B thermocouple and the main heating was controlled by an infrared pyrometer. The pyrometer was calibrated against a type $\mathrm{B}$ thermocouple at $1700^{\circ} \mathrm{C}$.

The density measurements were based on the Archimedean buoyancy method. Two Ir bobs were used. The bobs had masses of approximately 14 and $24 \mathrm{~g}$, respectively. Both were suspended from $0.5-\mathrm{mm}$ Ir wire. The measuring balance was a Mettler AE 100. It was interfaced to a personal computer for data gathering using a Mettler 012 Data Interface Module. The datalogging of buoyancy was performed at a 1- to 2-s interval and the results were computer averaged over time.

The procedure for density measurcment is to bring the sample to temperature, then load the Ir bob into the furnace from above, wait for thermal equilibrium, tare the balance and submerge the bob to a known depth in the liquid, and computer record the buoyancy. This procedure is repeated for the second bob, and the difference in buoyancy force, divided by the difference in submerged volume of Ir, yields the liquid density, c.g.,

$$
\rho=\left(B_{1}-B_{2}\right) /\left(V_{1}-V_{2}\right)
$$

where $\rho$ is the liquid density, $B_{1}$ and $B_{2}$ are the buoyancies, and $V_{1}$ and $V_{2}$ are the submerged volumes of the first and second bobs, respectively. The volume-temperature relationship of Ir was taken from Wimber ${ }^{1}$ to be

$$
\begin{aligned}
V_{1}= & 4.4601 \times 10^{-4}\left(100+1.994 \times 10^{-3} T-8.07 \times 10^{-8} T^{2}\right. \\
& \left.+4.599 \times 10^{-111} T^{\hat{3}}-1.052 \times 10^{-13} T^{4}\right)
\end{aligned}
$$

Buoyancy determinations have a precision of $\pm 0.1 \%$ at $1 \sigma$ and the density determinations were repeated with a precision of $\pm 0.3 \%$ at $1 \sigma$.

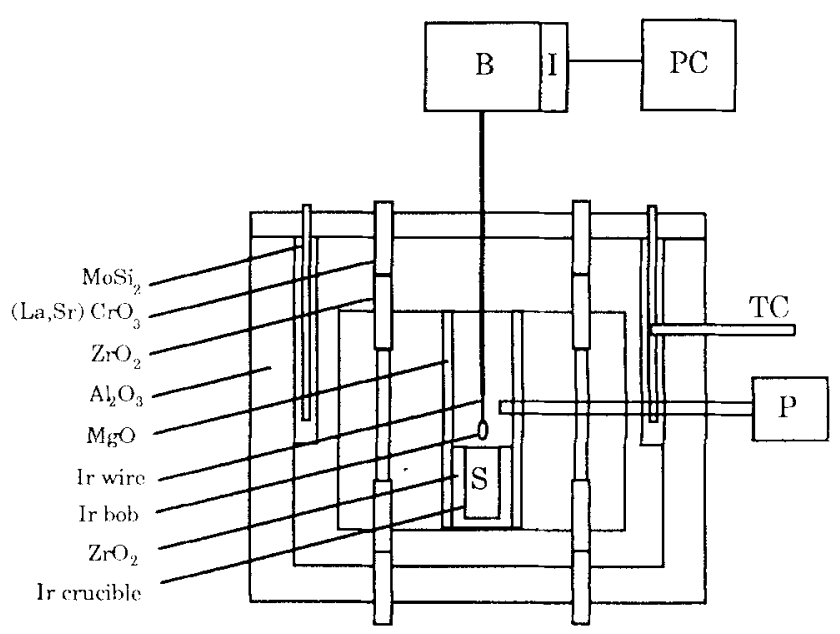

Fig. 1. Schematic of the assembly and furnace used for density measurements: (B) balance, (I) interface, (PC) computer, (TC) thermocouple, (P) pyrometer, (S) sample. 


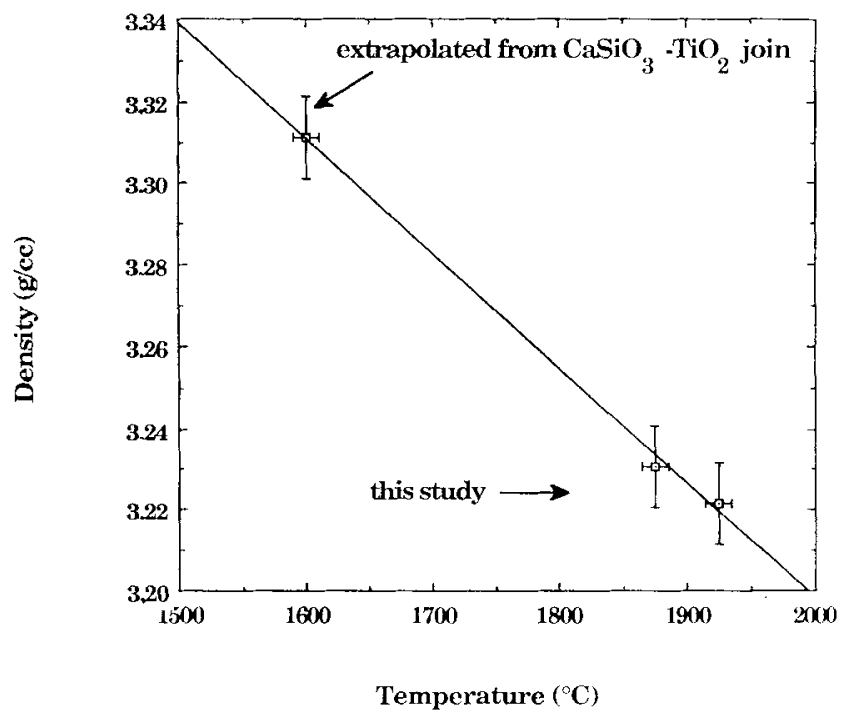

Fig. 2. Data for the temperature dependence of $\mathrm{TiO}_{2}$ density. Low-temperature data are from Dingwell (1991).

\section{II. Results}

The density of $\mathrm{TiO}_{2}$ liquid was determined at $1875^{\circ}$ and $1925^{\circ} \mathrm{C}$ using the double Ir bob Archimedcan method. The densities determined were $3.2308(9)$ and $3.2215(8) \mathrm{g} / \mathrm{cm}^{3}$ at $1875^{\circ}$ and $1925^{\circ} \mathrm{C}$, respectively. Figure 2 compares the results of this study with those of Dingwell ${ }^{2}$ obtained at temperatures up to $1600^{\circ} \mathrm{C}$ using $\mathrm{Pt}$ equipment on the $\mathrm{CaSiO}_{3}-\mathrm{TiO}_{2}$ join. The combined fit to the $1600^{\circ} \mathrm{C}$ extrapolated data point and the data of this study yields a temperature dependence of density given by

$$
\rho(T)=3.7611-0.000287\left({ }^{\circ} \mathrm{C}\right)
$$

This value of thermal expansivity is the same as that measured for melts on the $\mathrm{CaSiO}_{3}-\mathrm{TiO}_{2}$ join up to $80 \mathrm{~mol}_{\%} \mathrm{TiO}_{2}$. This value corresponds to a molar volume expansivity of $6.70 \times 10^{-3} \mathrm{~cm}^{3} /(\mathrm{mol} \cdot \mathrm{K})$ at 1500$)^{\circ} \mathrm{C}$. This value is in agreement with the results of multicomponent modeling of complex silicate melts that yield an end member $\mathrm{TiO}_{2}$ expansivity of $\left.(7.24 \pm 0.46) \times 10^{-3} \mathrm{~cm}^{3} /(\mathrm{mol} \cdot \mathrm{K})(\text { Lange and Carmichacl })^{3}\right)$.

Acknowledgments: I thank Kurt Klasinski for the computer interfacing software and Georg Hermannsdorfer for mechanical assistance

\section{References}

'R.T. Wimber, "High-Temperature Thermal Expansion of Iridium" (revised results), J. Appl. Plhys, 47, 5115 (1976).

'D. B. Dingwell, "Density of Some Titanium Bearing Silicate Liquids and the Compositional Dependence of the Partial Molar Volume of TiO Georhim. Cosmochim. Acka, in review.

${ }^{3}$ R. A. I ange and I. S. E. Carmichad. "Thermodynamic Properties of Sili. eate Melts with Emphasis on Density Thermal Expansion and Compressibility," Rev: Mineral., 24, 24-64 (1990) 